\title{
The Association between Carotid Intima-Media Thickness and Cognitive Impairment: A Systematic Review and Meta-Analysis
}

\author{
David Fresnais ${ }^{a, b}$ Mats B. Humble ${ }^{a}$ Susanne Bejerot ${ }^{a, c}$ Adrian Meehan ${ }^{a, d}$ \\ Brynjar Fure ${ }^{a, b}$
}

aSchool of Medical Sciences, Örebro University, Örebro, Sweden; ${ }^{b}$ Department of Internal Medicine, Central Hospital Karlstad, Karlstad, Sweden; 'University Health Care Research Center, Faculty of Medicine and Health, Örebro University, Örebro, Sweden; dDepartment of Geriatrics, Faculty of Medicine and Health, Örebro University, Örebro, Sweden

\section{Keywords}

Cognitive impairment · Dementia · Carotid intima-media thickness · Meta-analysis

\begin{abstract}
Background: Emerging evidence suggests that cognitive impairment $(\mathrm{Cl})$ and different etiologies of dementia, including Alzheimer's disease (AD), are associated with vascular risk factors and atherosclerosis. In clinical practice, carotid intima-media thickness (CIMT) measured by ultrasonography may be a marker of atherosclerosis. Many studies report increased CIMT in patients with dementia and $\mathrm{Cl}$ although a firm association has not yet been established. Aim: This systematic review and meta-analysis were conducted to study the relationship between CIMT, dementia, and $\mathrm{Cl}$. Methods: The literature search was performed according to the Preferred Reporting Items for Systematic Reviews and MetaAnalyses guidelines and included the following databases: Medline, Embase, Cochrane Library, and Epistemonikos. The search spanned from 2000 to 2020 and was limited to English and Scandinavian languages. Results: The main analysis of CIMT in subjects with $\mathrm{Cl}$ compared to subjects with no cognitive impairment ( $\mathrm{NCl})$ included 12 studies; 1,089 sub-
\end{abstract}

jects with $\mathrm{Cl}$ and 5,223 with $\mathrm{NCl}$. There was no significant difference in CIMT between the $\mathrm{Cl}$ and $\mathrm{NCl}$ groups. However, subgroup analyses revealed significantly higher CIMT in the mild cognitive impairment $(\mathrm{MCl})$ and dementia groups than the $\mathrm{NCl}$ group. In addition, patients with dementia had increased CIMT compared to patients with $\mathrm{MCl}$, and patients with AD demonstrated higher CIMT than those with vascular cognitive impairment (VCl). Conclusion: CIMT may be higher in subjects with $\mathrm{Cl}$ than in cognitively healthy subjects although no significant difference was observed in our main analysis. CIMT was higher in the dementia group than the $\mathrm{MCl}$ group and in the $\mathrm{AD}$ group compared to the $\mathrm{VCl}$ group.

(c) 2021 S. Karger AG, Basel

\section{Introduction}

Dementia is a syndrome of progressive decline in multiple cognitive domains such as memory, thinking, and behavior, sufficiently severe to affect activities of daily living [1]. Dementia has become a leading cause of disability and dependence in the elderly and results in enormous public burdens and family stress [2]. It is estimated that 50 million people suffer from dementia worldwide, and 
this number is expected to increase to 75 million by 2030 [3]. The global cost for dementia was approximately US $\$ 948$ billion in 2016 [4]. At present, there is no effective treatment that prevents or retards disease progression in dementia [2].

Alzheimer's disease (AD) is the most common form of dementia and accounts for about $60-70 \%$ of dementia cases $[2,5]$. Specific neuropathological hallmarks for $\mathrm{AD}$ are beta-amyloid $(A \beta)$ plaques and phosphorylated tau neurofibrillary tangles [6]. Second only to $\mathrm{AD}$, vascular dementia $(\mathrm{VaD})$ causes $20 \%$ of dementia cases [5]. $\mathrm{VaD}$ is believed to result from processes that damage blood vessels leading to reduced blood flow in the brain, with strokes or white matter lesions as a result [7]. Mild cognitive impairment (MCI) is the term for patients who show objective evidence of CI, sometimes defined as $<1.5$ standard deviations (SD) on any cognitive test according to the Petersen criteria, with preserved activities of daily living [8].

It is well-known that atherosclerosis is involved in the development of $\mathrm{VaD}$; however, increasing evidence shows that vascular pathology may also contribute to the development of AD [9]. Vascular pathology could possibly contribute to the development of $\mathrm{AD}$ through reduced cerebral blood flow resulting in the impairment of $\mathrm{A} \beta$ clearance [10] although the exact mechanisms are not yet known.

Carotid intima-media thickness (CIMT) investigation is a noninvasive procedure that uses ultrasound to measure atherosclerosis in clinical practice [11], usually on the far wall of the common or internal carotid arteries. Epidemiological studies have shown that atherosclerosis and vascular risk factors, including hypertension, diabetes, smoking, and hypercholesterolemia are associated with an increased risk of dementia [12]. However, the biomarkers that are currently available in clinical routine to assess the degree of atherosclerosis and vascular mechanisms in the pathogenesis of dementia and other forms of CI, for example, the Fazekas scale [13] in magnetic resonance imaging and computed tomography, are often examiner-dependent and not necessarily very sensitive. CIMT, being a precise and objective measurement, has therefore been suggested as a potentially useful marker to predict the risk of cognitive decline $[11,14,15]$. Increased CIMT has been reported as a risk factor for CI and poorer neuropsychological status in elderly patients $[16,17]$, as well as for $\mathrm{VaD}[18]$. Moreover, a previous meta-analysis, focusing on atherosclerosis in patients with AD exclusively, found that CIMT may be related to $\mathrm{AD}[14]$.
However, the association between CIMT and dementia has not been clearly established, and the contribution of vascular pathology in different forms of dementia and MCI is currently a matter of investigation $[14,18]$. The present meta-analysis of existing studies was performed to evaluate the potential association between CIMT and different etiologies of dementia.

\section{Methods}

\section{Search Strategy}

The following databases were searched systematically by a trained information specialist to identify articles on dementia and CIMT from 2000 to 2020: Medline, Embase, Cochrane Library, and Epistemonikos. We used the following search terms: "cognitive screening," "cognition," "cognitive tests," "mental status," "cognitive function," dementia tests," "dementia," "Alzheimer's disease," "Alzheimer's dementia," "vascular dementia," "Lewy body dementia," "normal pressure hydrocephalus," "mixed dementia," "IMT," "carotid intima-media thickness," and "intimamedia thickness measurements." The literature search was limited to studies in English or Scandinavian language. The full search strategy is shown in online suppl. Table 1; for all online suppl. material, see www.karger.com/doi/10.1159/000518295.

\section{Selection Criteria}

The present systematic review and meta-analysis were performed according to the preferred reporting items for systematic reviews and meta-analyses (PRISMA) guidelines. Reviewers applied eligibility criteria and independently screened titles and abstracts for inclusion after the removal of duplicated literature, followed by the assessment of full-text records according to the selection criteria. Eligible trials fulfilled the following prespecified criteria (PICOS): (1) population: persons with dementia or CI; (2) intervention: measurement of CIMT; (3) comparison: (a) persons without dementia if compared to persons with dementia, (b) persons without MCI or dementia if compared to persons with MCI, and (c) persons with VCI if compared to AD; (4) outcome: the association between CI and CIMT; and (5) observational studies.

\section{Data Extraction and Analyses}

Two investigators extracted data from the included articles independently of each other using a designed table and compared data to ensure accuracy. The general characteristics of included studies were obtained as follows: first author of the study, year of publication, country and setting of research, study design, number of patients included, patient demographics including age and sex distribution, location and side of CIMT measurement, and results from cognitive testing. Study investigators were not contacted for unreported data or additional details. The qualified studies included several subtypes of dementia. Data were extracted regarding the criteria used for diagnosing dementia and CI and for the measurement of mean and maximum CIMT.

\section{Statistical Methods}

Differences in CIMT between persons with (1) CI and NCI, (2) dementia and NCI, (3) dementia and MCI, (4) MCI and NCI, and 
Fig. 1. PRISMA 2020 flow chart showing process of identification of studies. CIMT, carotid intima-media thickness; n., number; PRISMA, Preferred Reporting Items for Systematic Reviews and Meta-Analyses.
Identification of studies via databases and registers

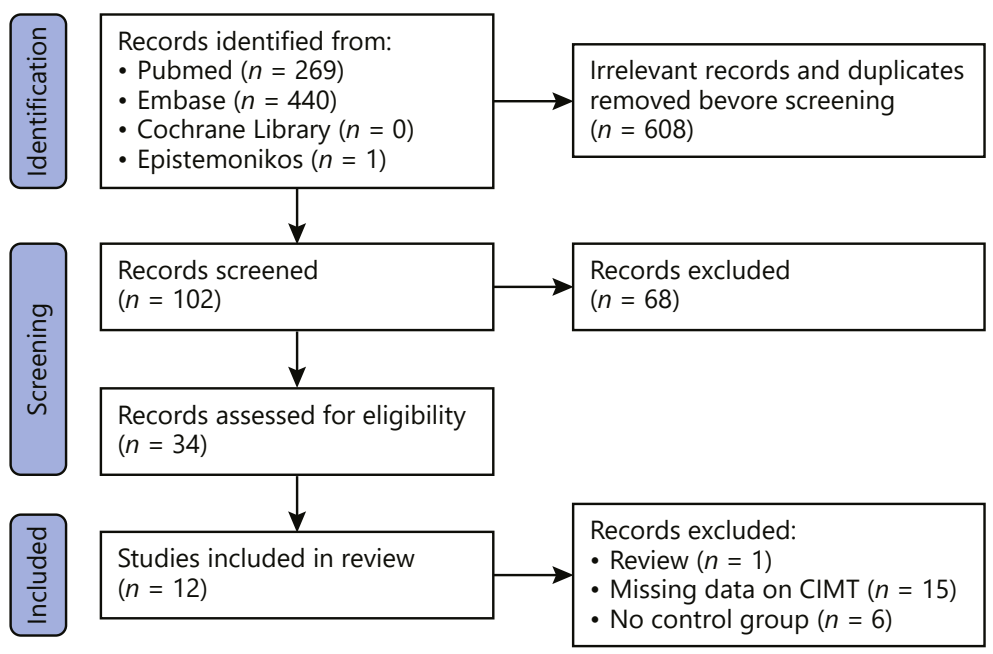

(5) $\mathrm{AD}$ and $\mathrm{VaD}$ were analyzed. Values of mean CIMT with SD were extracted.

SD was calculated using the formula presented in the Cochrane Handbook for studies reporting confidence interval (CI) instead of SD [19]. Statistical analyses were carried out using RevMan 5.4.1 [20].

Quality Assessment and Risk of Bias

Two investigators independently assessed the quality of studies included in the meta-analyses using Critical Appraisals Skills Programme (CASP) [21] and Center for Evidence-Based Management (CEBM) checklists [22]. In assessing the studies included in this meta-analysis, the CASP checklists designed for case-control and cohort studies were used, and for cross-sectional studies, the CEBM critical appraisal checklist for cross-sectional studies was used. The Grading of Recommendations, Assessment, Development and Evaluations (GRADE) [23] tool was used to assess the overall confidence in the effect estimates across studies for each pooled outcome.

Disagreements between Individual Judgments

Any disagreements in study selection, data extraction, and quality assessment of studies were resolved by consensus.

\section{Results}

\section{Literature Search}

The process of identifying relevant studies is shown in Figure 1. In total, 102 relevant studies were identified after the removal of duplicates. After screening titles and abstracts, 68 records were excluded and 34 were reviewed in full text for eligibility. Finally, 12 studies met our inclu- sion criteria and 22 were deemed ineligible; reasons for exclusion are shown in online suppl. Table 2.

\section{Study Characteristics}

The main characteristics of the 12 studies included in the meta-analyses, diagnosis and ascertainment of diagnosis, and CIMT values and location of CIMT measurements are shown in Tables 1-3, respectively. The included studies were published between 2009 and 2019. Of these, 5 were cross-sectional studies, 3 were prospective cohort studies, and 4 were case-control studies. The diagnostic criteria for dementia and MCI varied across studies. The Diagnostic and Statistical Manual of Mental Disorders, Fourth Edition [24] and the Mini-Mental State Examination [25] were the most frequently used instruments for diagnosing dementia and MCI, respectively.

\section{Meta-Analysis of Results}

To evaluate the relationship between CIMT and CI, we explored the differences in mean CIMT between patients with CI and NCI. Subgroup analyses were performed to assess differences in CIMT between persons with MCI and NCI, dementia and MCI, dementia and NCI, and between $\mathrm{AD}$ and VCI.

\section{Mean Difference of CIMT in Patients with and} without CI

Of the 12 included studies [26-37], 9 [26-30, 32-34, 37], provided data for the main analysis of CIMT in pa- 


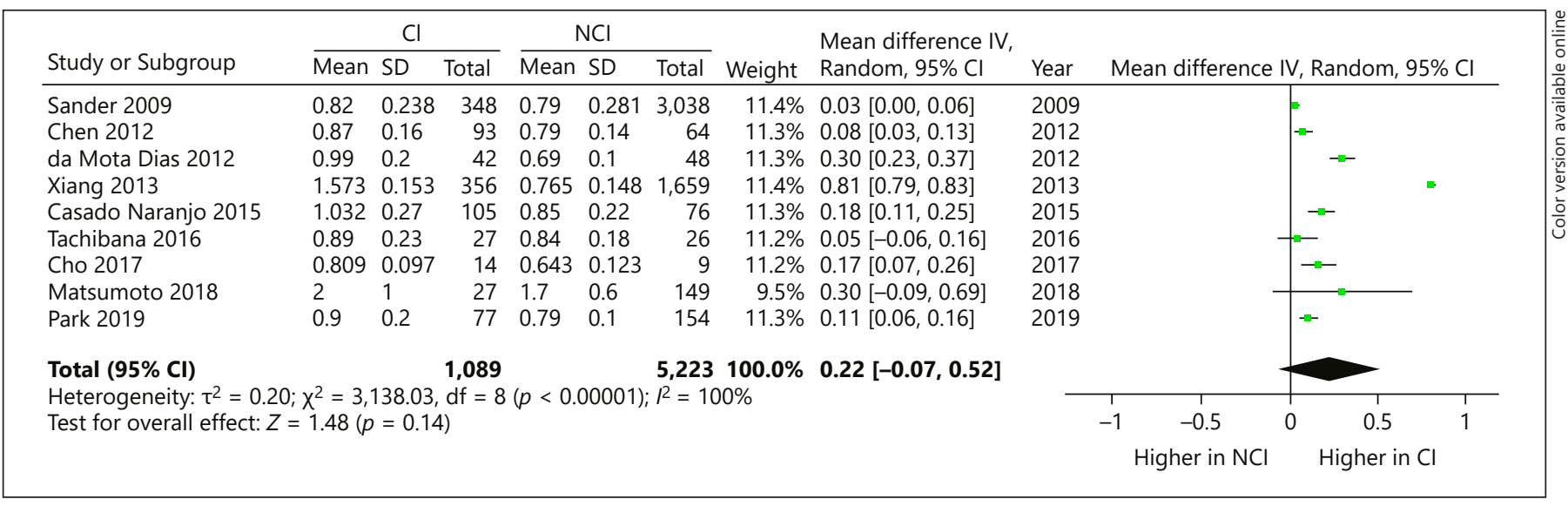

Fig. 2. Forest plot showing MD in CIMT between persons with CI and NCI. CI, cognitive impairment; NCI, no cognitive impairment; SD, standard deviation; mm, millimeters; CIMT, carotid intima-media thickness; MD, mean difference.

Table 1. General characteristics of included studies

\begin{tabular}{|c|c|c|c|c|c|c|c|}
\hline Author of publication & $\begin{array}{l}\text { Study } \\
\text { design }\end{array}$ & Country & Setting & $N$ & $\begin{array}{l}\text { Age, } \\
N(\mathrm{SD})\end{array}$ & $\begin{array}{l}\text { Sex, } \\
N(\%)\end{array}$ & Education \\
\hline Park et al. [60] & 1 & South Korea & Community health centers & 231 & $77(4)$ & F: $186(80.5)$ & $\begin{array}{l}\text { Elementary school } 72.7 \% \text {; middle and } \\
\text { high school } 25.5 \% \text {; college or more } 1.7 \%\end{array}$ \\
\hline Matsumoto et al. [61] & 1 & Japan & University hospital & 176 & $65(10)$ & F: $98(55.7)$ & Years of education, mean 14.5 (SD 3.0) \\
\hline Rouch et al. [62] & 2 & France & University hospital & 375 & $75(7)$ & F: $246(65.6)$ & $\begin{array}{l}\text { University } 49.6 \% \text {; middle or high school } \\
27.1 \% \text {; primary school } 23.3 \%\end{array}$ \\
\hline Cho et al. [63] & 1 & South Korea & $\begin{array}{l}\text { University hospital outpatient } \\
\text { clinic }\end{array}$ & 53 & NR & NR & NR \\
\hline Tachibana et al. [64] & 1 & Japan & University hospital & 76 & NR & F: $43(56.6)$ & NR \\
\hline $\begin{array}{l}\text { Casado Naranjo et al. } \\
\text { [65] }\end{array}$ & 3 & Spain & University hospital & 181 & NR & F: $98(54.1)$ & $\begin{array}{l}\text { Education } \leq 6 \text { years, } 55.2 \% \text { in the aMCl } \\
\text { and } 55.3 \% \text { in the } \mathrm{NCl} \text { group }\end{array}$ \\
\hline Xiang et al. [66] & 1 & China & University hospital & 2015 & 69 & F: 981 (48.7) & NR \\
\hline Chen et al. [67] & 1 & China & Hospital outpatient clinic & 157 & $55(7)$ & F: 76 (48.4) & NR \\
\hline Dias Eda et al. [68] & 1 & Brazil & Specialized hypertension center & 90 & NR & $F: 56(62.2)$ & NR \\
\hline Stefanova et al. [69] & 1 & Serbia & University hospital & 533 & NR & F: $269(50.5)$ & NR \\
\hline Viticchi et al. [70] & 2 & Italy & University hospital & 117 & $76(6)$ & F: $57(48.7)$ & Years of education, mean 7.4 (SD 2.6) \\
\hline Sander et al. [71] & 2 & Germany & $\begin{array}{l}\text { University hospital and primary } \\
\text { care }\end{array}$ & 3,386 & 68 & $\mathrm{~F}: 2000$ (59.1) & $\begin{array}{l}\text { Lower elementary } 90 \% \text {; intermediary } \\
\text { education level } 7 \% \text {; college or university } \\
3 \%\end{array}$ \\
\hline
\end{tabular}

Study design: 1 = cross-sectional, 2 = prospective cohort, 3 = case control. NR, not reported; SD, standard deviation; F, female; NCl, no cognitive impairment; $\mathrm{aMCl}$, amnestic mild cognitive impairment.

tients with CI and NCI involving 6,312 subjects, 1,089 with CI, and 5,223 with NCI. Included studies had sample sizes ranging from 53 [37] to 3,386 [32]. The inverse variance model showed no statistically significant difference of mean CIMT between the CI and NCI groups (mean difference $[\mathrm{MD}]=0.22 ; 95 \%$ confidence interval, -0.07 to $0.52 ; p=0.14)$. Since there was evidence of large heterogeneity, a random effects model was used to combine the 


\begin{tabular}{|c|c|c|c|c|c|c|c|c|c|c|c|}
\hline \multirow[b]{2}{*}{ Study or Subgroup } & \multicolumn{3}{|c|}{$\mathrm{MCl}$} & \multicolumn{3}{|c|}{$\mathrm{NCl}$} & \multirow[b]{2}{*}{ Weight } & \multirow{2}{*}{$\begin{array}{l}\text { Mean difference IV, } \\
\text { Random, } 95 \% \mathrm{CI}\end{array}$} & \multirow[b]{2}{*}{ Year } & \multirow{2}{*}{\multicolumn{2}{|c|}{ Mean difference IV, Random, 95\% Cl }} \\
\hline & Mean & SD & Total & Mean & SD & Total & & & & & \\
\hline Chen 2012 & 0.87 & 0.16 & 93 & 0.79 & 0.14 & 64 & $35.0 \%$ & $0.08[0.03,0.13]$ & 2012 & & - \\
\hline Casado Naranjo 2015 & 1.032 & 0.27 & 105 & 0.85 & 0.22 & 76 & $23.0 \%$ & $0.18[0.11,0.25]$ & 2015 & & \\
\hline Cho 2017 & 0.743 & 0.226 & 11 & 0.643 & 0.123 & 9 & $7.0 \%$ & $0.10[-0.06,0.26]$ & 2017 & & \\
\hline Park 2019 & 0.9 & 0.2 & 77 & 0.79 & 0.1 & 154 & $34.9 \%$ & $0.11[0.06,0.16]$ & 2019 & & - \\
\hline \multirow{2}{*}{\multicolumn{7}{|c|}{$\begin{array}{l}\text { Total }(\mathbf{9 5} \% \mathbf{C I}) \\
\text { Heterogeneity: } \tau^{2}=0.00 ; \chi^{2}=5.46, \mathrm{df}=3(p=0.14) ; R^{2}=45 \% \\
\text { Test for overall effect: } Z=5.13(p<0.00001)\end{array}$}} & $100.0 \%$ & $0.12[0.07,0.16]$ & & & \\
\hline & & & & & & & & & & $\begin{array}{cc}1 & \\
-0.2 & -0.1\end{array}$ & 0.2 \\
\hline & & & & & & & & & & Higher in $\mathrm{NCl}$ & Higher in $\mathrm{MCl}$ \\
\hline
\end{tabular}

Fig. 3. Forest plot showing MD in CIMT between persons with MCI and NCI. MCI, mild cognitive impairment; NCI, no cognitive impairment; SD, standard deviation; $\mathrm{mm}$, millimeters; CIMT, carotid intima-media thickness; $\mathrm{MD}$, mean difference.

Table 2. Diagnosis and diagnostic criteria

\begin{tabular}{|c|c|c|c|c|}
\hline Park et al. [60] & $\mathrm{MCl}$ & $\mathrm{NCl}$ & K-MMSE, interview, neuropsychological assessment & Same as for $\mathrm{Cl}$ group \\
\hline Matsumoto et al. [61] & $\mathrm{Cl}$ & $\mathrm{NCl}$ & $\begin{array}{l}\text { MMSE, the clock drawing test, subjective forgetfulness, the } \\
\text { WMS-R logical memory test according to ADNI }\end{array}$ & Same as for $\mathrm{Cl}$ group \\
\hline Rouch et al. [62] & Dementia & $\mathrm{MCl}$ & DSM-IV, MMSE, cognitive battery & Petersen's criteria \\
\hline Tachibana et al. [64] & $\mathrm{AD}$ and $\mathrm{VaD}$ & $\mathrm{NCl}$ & $\begin{array}{l}\text { Clinical and radiological diagnosis. DSM-V and/or NINCDS- } \\
\text { ADRDA (AD), NINDS-AIREN (VaD) }\end{array}$ & MMSE $\geq 26$ \\
\hline Casado Naranjo et al. [65] & $\mathrm{MCl}$ & $\mathrm{NCl}$ & MMSE and neuropsychological testing & MMSE $\geq 27$ \\
\hline Xiang et al. [66] & $\mathrm{Cl}$ & $\mathrm{NCl}$ & MMSE $<24$ & MMSE \\
\hline Stefanova et al. [69] & $A D$ & $\mathrm{VCl}$ & NINCDS-ADRDA and DSM-IV & NINDS-AIREN \\
\hline Viticchi et al. [70] & $A D$ & $\mathrm{MCl}$ & Modified DSM-IV and NINCDS-ADRDA & $\begin{array}{l}\text { Petersen's criteria; } \\
\text { MMSE > } 24\end{array}$ \\
\hline Sander et al. [71] & $\mathrm{Cl}$ & $\mathrm{NCl}$ & $6 \mathrm{CIT}$ & $6 \mathrm{CIT}$ \\
\hline
\end{tabular}

$\mathrm{Cl}$, cognitive impairment; $\mathrm{NCl}$, no cognitive impairment; $\mathrm{MCl}$, mild cognitive impairment; $\mathrm{AD}$, Alzheimer's disease; VaD, vascular dementia; $\mathrm{VCl}$, vascular cognitive impairment; DSM-IV, Diagnostic and Statistical Manual of Mental Disorders 4th edition; MMSE, Mini-Mental State Examination; K-MMSE, Korean Mini-Mental State Examination; WMS-R, Wechsler Memory Scale-Revised; ADNI, Alzheimer's Disease Neuroimaging Initiative; CDR, Clinical Dementia Rating Scale; SNSB, Seoul Neuropsychological Screening Battery; MoCA, Montreal Cognitive Assessment; NINCDS-ADRDA, National Institute of Neurological and Communicative Diseases and Stroke/Alzheimer's Disease and Related Disorders Association; NINDS-AIREN, National Institute of Neurological Disorders and Stroke and Association Internationale pour la Recherche et l'Enseignement en Neurosciences; 6CIT, Six-Item Cognitive Impairment Test.

data. The forest plot for the MD in CIMT between the CI and NCI groups is shown in Figure 2.

Subgroup analyses revealed higher mean CIMT in subjects with $\mathrm{MCI}(\mathrm{MD}=0.12 ; 95 \%$ confidence interval, $0.07-0.16 ; p<0.01)$ and dementia $(\mathrm{MD}=0.11 ; 95 \%$ con- fidence interval, $0.00-0.23 ; p=0.05$ ) than NCI subjects and is shown in Figures 3 and 4, respectively. In addition, mean CIMT was higher in subjects with dementia compared to MCI ( $\mathrm{MD}=0.07 ; 95 \%$ confidence interval, $0.00-0.13 ; p=0.05)$ as well as in subjects with AD com- 


\begin{tabular}{|c|c|c|c|c|c|c|c|c|c|c|}
\hline \multirow[b]{2}{*}{ Study or Subgroup } & \multicolumn{3}{|c|}{ Dementia, mm } & \multicolumn{3}{|c|}{$\mathrm{NCl}, \mathrm{mm}$} & \multirow[b]{2}{*}{ Weight } & \multirow{2}{*}{$\begin{array}{l}\text { Mean difference IV, } \\
\text { Random, } 95 \% \mathrm{Cl}\end{array}$} & \multirow[b]{2}{*}{ Year } & \multirow[b]{2}{*}{ Mean difference IV, Random, 95\% Cl } \\
\hline & Mean & SD & Total & Mean & SD & Total & & & & \\
\hline Tachibana 2016 & 0.89 & 0.23 & 27 & 0.84 & 0.18 & 26 & $46.8 \%$ & $0.05[-0.06,0.16]$ & 2016 & $千-$ \\
\hline Cho 2017 & 0.809 & 0.097 & 14 & 0.643 & 0.123 & 9 & $53.2 \%$ & $0.17[0.07,0.26]$ & 2017 & - \\
\hline \multirow{3}{*}{\multicolumn{7}{|c|}{$\begin{array}{l}\text { Total }(\mathbf{9 5 \%} \mathbf{~ C l}) \\
\text { Heterogeneity: } \tau^{2}=0.00 ; \chi^{2}=2.42, \mathrm{df}=1(p=0.12) ; R^{2}=59 \% \\
\text { Test for overall effect: } Z=1.93(p=0.05)\end{array}$}} & $100.0 \%$ & $0.11[-0.00,0.23]$ & & \\
\hline & & & & & & & & & & $\begin{array}{cccccc} & & & & \\
-0.2 & -0.1 & 0 & 0.1 & 0.2\end{array}$ \\
\hline & & & & & & & & & & Higher in dementia \\
\hline
\end{tabular}

Fig. 4. Forest plot showing MD in CIMT between persons with dementia and NCI. NCI, no cognitive impairment; SD, standard deviation; mm, millimeters; CIMT, carotid intima-media thickness; MD, mean difference.

Table 3. CIMT measurements in a $\mathrm{Cl}$ group compared to a $\mathrm{NCl}$ group

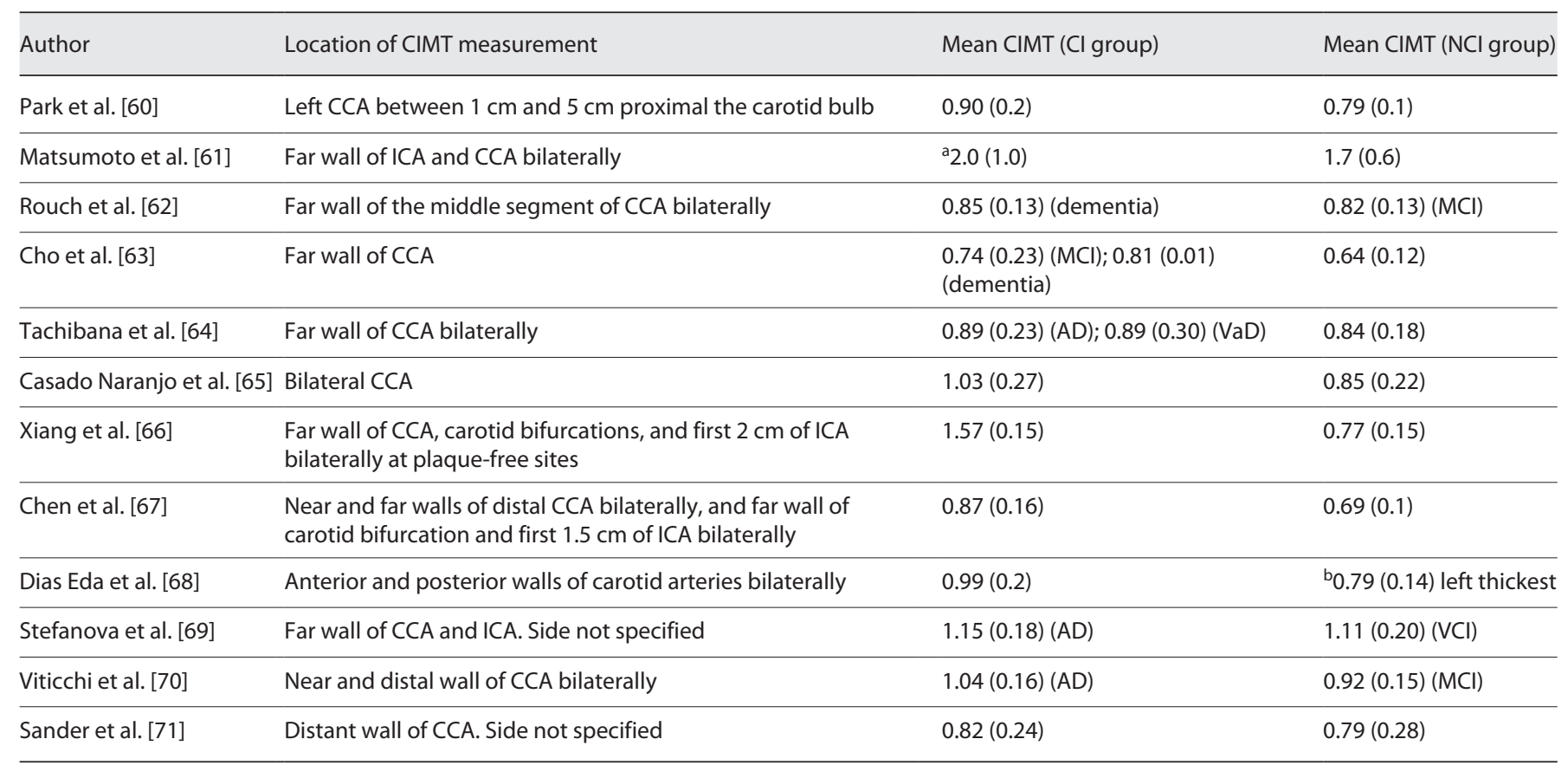

CIMT, carotid intima-media thickness; $\mathrm{Cl}$, cognitive impairment; $\mathrm{NCl}$, no cognitive impairment; $\mathrm{MCl}$, mild cognitive impairment; $\mathrm{AD}$, Alzheimer's disease; $\mathrm{VaD}$, vascular dementia; $\mathrm{VCl}$, vascular cognitive impairment; CCA, common carotid artery; ICA, internal carotid artery. ${ }^{\mathrm{a}}$ Mean max CIMT. ${ }^{\mathrm{b}}$ Left, highest value.

pared to $\mathrm{VaD}(\mathrm{MD}=0.04 ; 95 \%$ confidence interval, $0.00-0.07 ; p=0.03)$, shown in Figures 5 and 6, respectively.

\section{Assessment of Quality of the Included Studies}

Assessments according to the CASP and CEBM checklists are presented in Table 4. Assessments of our confidence in the pooled estimates according to GRADE are presented in Table 5. The confidence in the effect estimates was assessed as low or very low, implying that further research is very likely to affect the results.

\section{Discussion}

This systematic review and meta-analysis were performed to investigate the relationship between CIMT and CI including dementia and MCI. The meta-analysis showed that CIMT of the CI and NCI groups did not differ significantly. However, the subgroup analyses, generated by analyzing MCI and dementia separately, revealed a significant difference with higher CIMT in the MCI and dementia groups than the NCI group. Also, subjects with dementia had significantly higher CIMT than subjects 


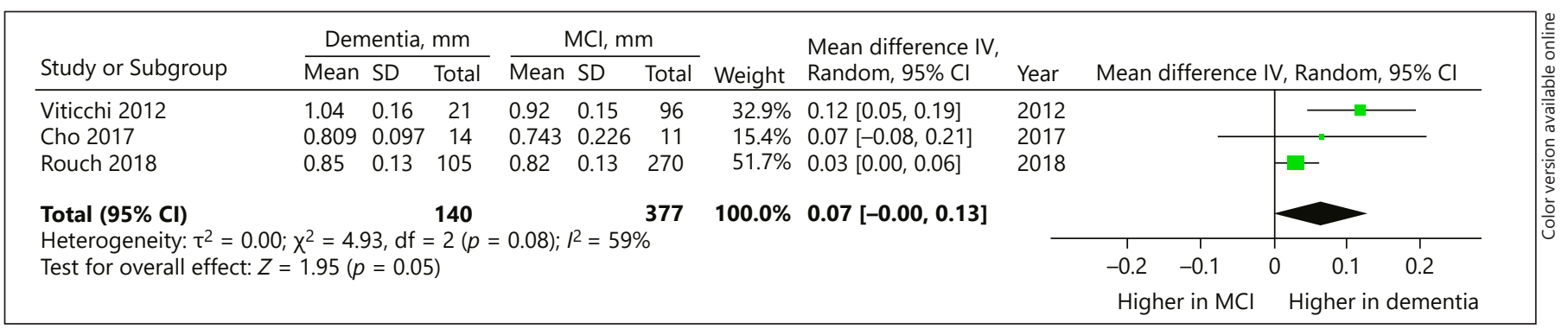

Fig. 5. Forest plot showing MD in CIMT between persons with dementia and MCI. MCI, mild cognitive impairment; SD, standard deviation; mm, millimeters; CIMT, carotid intima-media thickness; MD, mean difference.

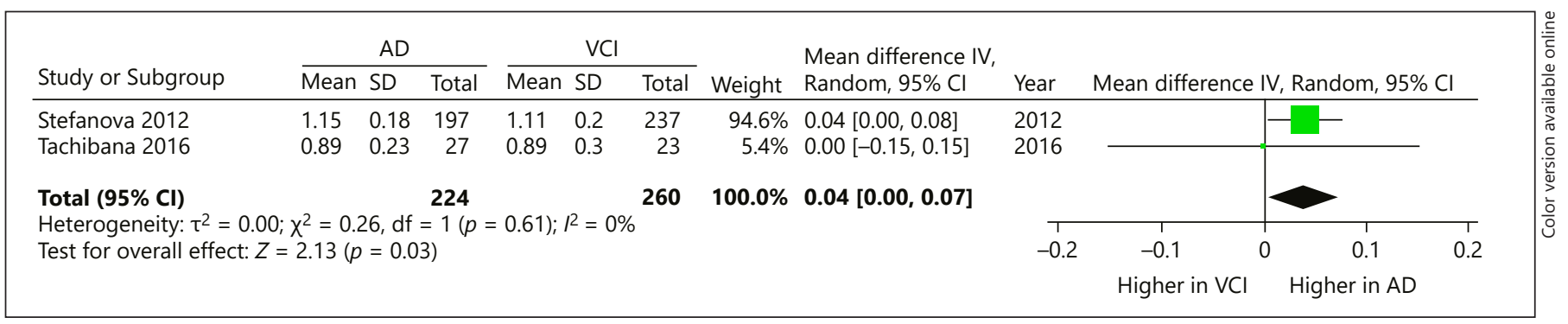

Fig. 6. Forest plot showing MD in CIMT between persons with $\mathrm{AD}$ and VCI. AD, Alzheimer's disease; VCI, vascular cognitive impairment; SD, standard deviation; mm, millimeters; CIMT, carotid intima-media thickness; $\mathrm{MD}$, mean difference.

with $\mathrm{MCI}$, and CIMT was higher in subjects with $\mathrm{AD}$ compared to VCI.

A number of studies have explored the relationship between CIMT and CI, reporting diverging results [16, 17, 38]. Higher CIMT has been associated with lower MMSE scores [39], reduced cognitive function [40], and has been shown to predict impaired cognitive function later in life when measured in middle-aged persons [41]. A recent longitudinal study that followed 462 individuals for 20 years found that higher CIMT in midlife increases the risk of cerebral small vessel disease and even subsequent all-cause dementia [18]. Three additional prospective studies - the Cardiovascular Health Study [42], the Rotterdam Study [43], and the Baltimore Longitudinal Study of Aging [44] - have reported a significant and independent association between CIMT and dementia. These results were not reproduced in our main analysis of CIMT and CI although a nonsignificant trend toward higher CIMT in CI subjects was observed. This nonsignificant association was supported by the subgroup analyses in which both the dementia and MCI groups demonstrated significantly higher CIMT than the NCI group. CIMT was treated as a continuous variable in our analy-

Carotid Intima-Media Thickness and

Cognitive Impairment ses, and studies reporting only dichotomous measurements of CIMT were excluded. This may be important since the 3 aforementioned longitudinal studies found increased hazard ratios of dementia only for the highest quintile of CIMT [42, 43], or when CIMT was defined as a dichotomous variable [44], suggesting a "threshold effect."

In contrast, the Three-City study, a longitudinal study including 6,025 subjects, reported that carotid plaques, but not mean CIMT, predicted subsequent dementia [38]. The Three-City study measured CIMT in a plaquefree zone, while the Cardiovascular Health Study and the Rotterdam Study measured CIMT in all carotid segments. Therefore, the association with CIMT and dementia could instead reflect an association with carotid plaques per se. This was also observed in the current meta-analysis, where CIMT values ranged from 0.82 to $2.0 \mathrm{~mm}$ in the CI group, and from 0.64 to $1.7 \mathrm{~mm}$ in the NCI group, where the higher values could represent heterogeneity due to measurement in areas with plaque. A postmortem study found that carotid stenosis was associated with increased odds for dementia, while CIMT showed no such association [45]. 


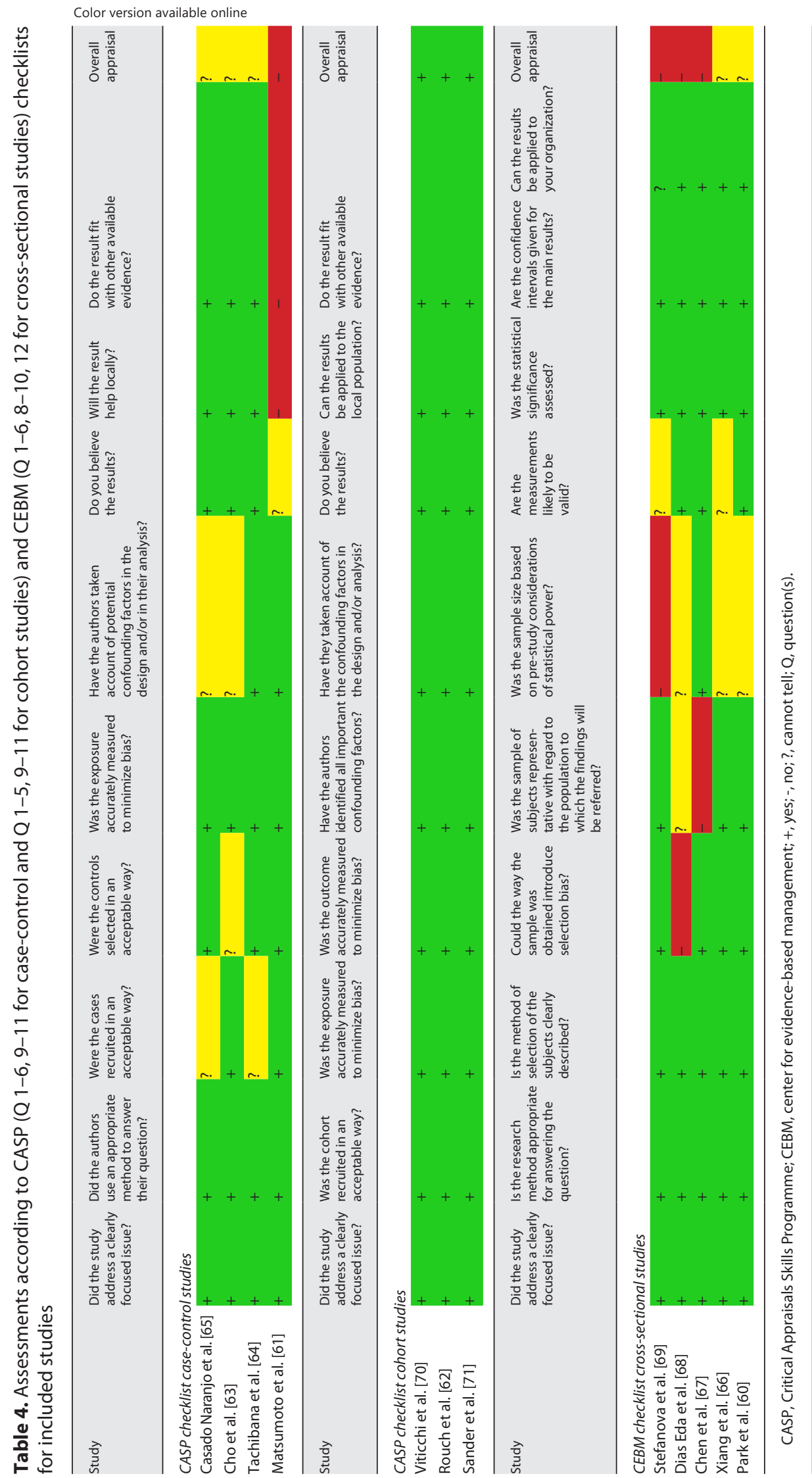




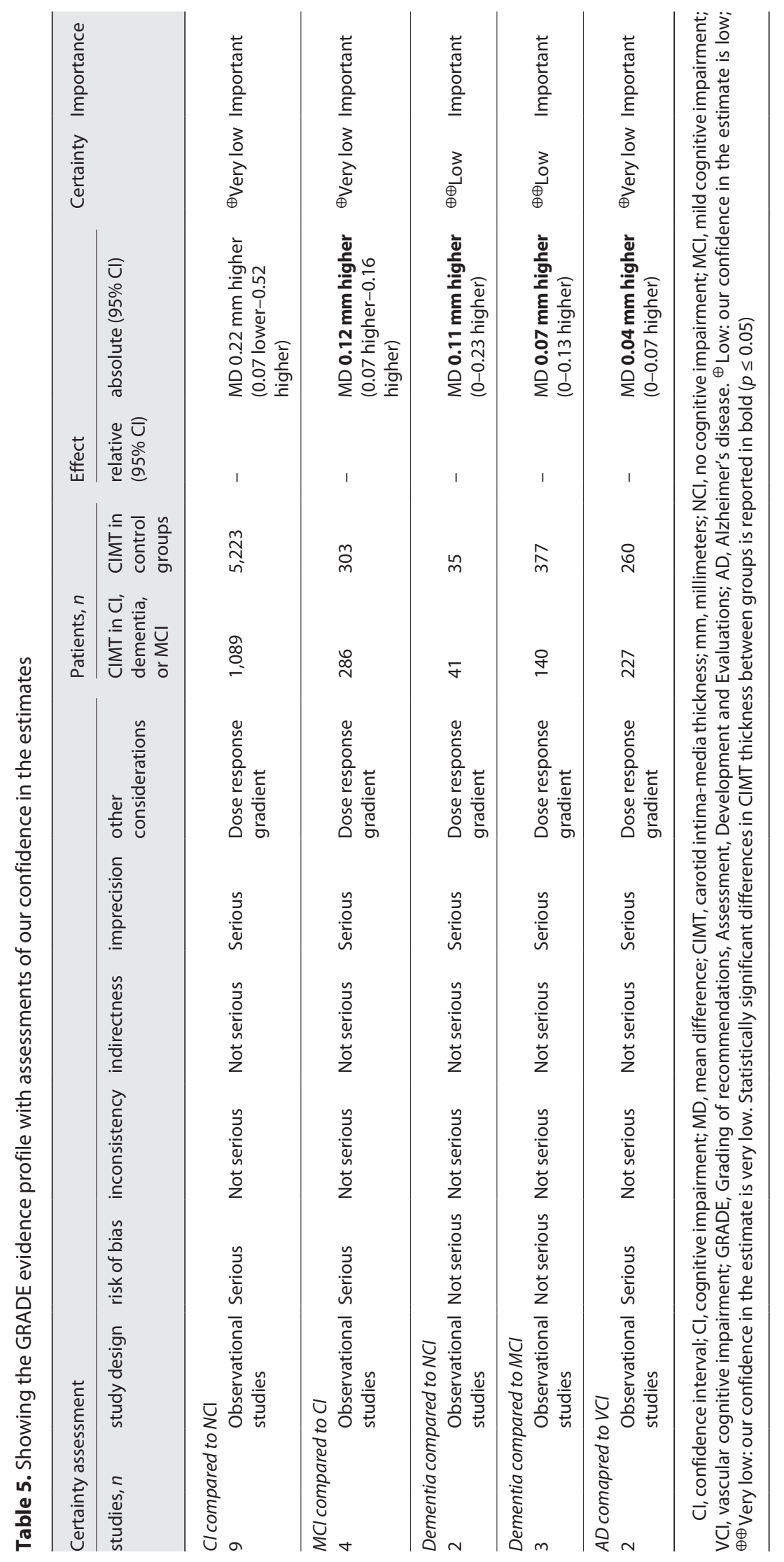


On the other hand, other longitudinal studies have, in accordance with our analysis of dementia and NCI, demonstrated that CIMT, as a continuous variable, is associated with an increased risk of MCI and dementia $[17,18]$. As for dementia, previous studies that have explored the relationship between CIMT and MCI have showed diverging results [34, 46, 47]. Also, no agreement has been reached regarding the role of CIMT as a predictor of conversion from MCI to dementia [17, 35, 37]. Data from our subgroup analyses revealed that dementia patients had higher CIMT values than MCI patients, which could provide support for studies suggesting a link between CIMT and conversion from MCI to dementia $[17,36]$.

The vascular alterations indicated by increased CIMT could possibly be involved in the development of CI through multiple mechanisms. First, increase in CIMT can reduce blood flow to the brain, thereby affecting different cognitive domains $[48,49]$. In addition, increased CIMT is associated with vascular pathologies such as hypertension and atherosclerosis that could be related to structural changes in the brain, including white matter lesions associated with cerebral small vessel disease, and atrophy, that may in turn affect cognition [50, 51]. Moreover, white matter lesions caused by silent brain micro infarcts and brain micro hemorrhages could contribute to $\mathrm{CI}[33,52]$. Interestingly, our analyses revealed that CIMT was higher in the AD than the VCI group that included both $\mathrm{VaD}$ and vascular MCI. Although this association was only statistically significant and not necessarily of clinical significance, it may support the growing evidence that vascular pathology is involved not only in the development of $\mathrm{VaD}$ but even in $\mathrm{AD}[9,53]$. Vascular risk factors measured in midlife, including hypertension, diabetes, smoking [54], and hypercholesterolemia [55] have been associated with the risk of $\mathrm{AD}$, and might accelerate AD progression [56]. Indeed, the association between CIMT and AD is supported in a previous metaanalysis [14]. Vascular risk factors have been associated with higher levels of brain $\mathrm{A} \beta$ deposition measured using positron emission tomography [57]. A possible mechanism for this association, a dysfunctional glymphatic system with abnormal arterial impulse propagation compromising brain clearance of $A \beta$, has recently been demonstrated in vivo in patients with AD [58]. Furthermore, hypoperfusion and hypoxia have been associated with increased $A \beta$ deposition in the brain and oxidative stress that could contribute to CI [59].

The limitations of this meta-analysis include that some of the reported studies had small sample sizes and that our subgroup analyses only included between 2 and 4 studies. Moreover, due to the large heterogeneity of studies, a random effects model was used for our analyses. There is a risk that some studies in the literature were overlooked since we did not include conference abstracts in the article selection process or contact the authors when data were missing or only presented as odds ratios. An additional limitation is the heterogeneity in study samples, with some studies measuring CIMT in midlife and others in late life (age $>65$ years). This could be important since some major vascular risk factors have been associated with an increased risk of dementia when they occur in midlife in particular, but not necessarily later in life [57]. However, studies that measured CIMT in late life have also reported increased hazard ratios of all-cause dementia $[43,44]$. When MCI or dementia is diagnosed in persons included in research studies, researchers may sometimes follow-up of these persons more carefully than controls without CI, which may lead to a bias in the sample studied. Finally, diagnostic criteria for CI varied across the included studies. Some of the strengths of the present meta-analysis is that the systematic literature search was performed by a trained information specialist as well as the presentation of a transparent methodology of sorting, including, and assessing studies.

In conclusion, the results from the current systematic review and meta-analysis suggest that CIMT may be higher in subjects with CI than cognitively healthy subjects although no significant difference was observed in our main analysis. This potential association is supported by subgroup analyses which showed that CIMT was significantly higher in subjects with MCI and dementia than subjects with NCI. In addition, the dementia group had significantly higher CIMT than the MCI group, and CIMT was also higher in subjects with $\mathrm{AD}$ than those with VCI. However, many of the studies had methodological weaknesses affecting our confidence in the results. Therefore, further research with larger, high-quality studies is needed to clarify the potential association between CI and CIMT.

\section{Acknowledgements}

The authors would like to thank information specialist Maj Millom at the Hospital Library, Central Hospital Karlstad for performing the literature search and for excellent support and assistance with the present systematic review and meta-analysis. 


\section{Statement of Ethics}

All investigations were conducted in accordance with the Declaration of Helsinki. The study followed the ethical guidelines of the Regional Ethics Committee of Uppsala, Sweden and is exclusively based on published literature.

\section{Conflict of Interest Statement}

The authors have no conflicts of interest to declare.

\section{Funding Sources}

The study was funded by Örebro University School of Medical Sciences, Örebro, Sweden, and Central Hospital Karlstad, Karlstad, Sweden.

\section{Author Contributions}

D.F. and B.F. conceived and designed the study, and A.M., M.H., and S.B. helped to establish the final PICOS criteria. D.F. and B.F. performed the data extraction, quality assessment of studies, and meta-analyses. D.F. wrote the first draft of the manuscript and revisions of drafts. B.F. reviewed and contributed to revision of all the drafts. All authors revised the manuscript critically for important intellectual content.

\section{Data Availability Statement}

All data generated or analyzed during this study are included in this article and its online suppl. material files. Further inquiries can be directed to the corresponding author.

\section{References}

1 Arvanitakis Z, Shah RC, Bennett DA. Diagnosis and management of dementia: review. JAMA. 2019 Oct 22;322(16):1589-99.

2 World Health Organization. Global action plan on the public health response to dementia 2017-2025. Geneva: World Health Organization; 2017. Available from: https: //apps.who.int/iris/bitstream/hand le/10665/259615/9789241513487-eng.pdf; jsessionid=BDBE765EEB92F5EF5320A2F 12489EA51 ? sequence $=1$.

3 Alzheimer's Disease International. Policy brief for G8 heads of government. The global impact of dementia 2013-2050. London: Alzheimer's Disease International; 2013. Available from: http://www.alz. co.uk/research/GlobalImpactDementia2013.pdf.

$4 \mathrm{Xu} \mathrm{J}$, Zhang Y, Qiu C, Cheng F. Global and regional economic costs of dementia: a systematic review. The Lancet. 2017 Dec;390: S47.

5 Rizzi L, Rosset I, Roriz-Cruz M. Global epidemiology of dementia: Alzheimer's and vascular types. Biomed Res Int. 2014;2014: 908915.

6 Selkoe DJ. Alzheimer's disease: genes, proteins, and therapy. Physiol Rev. 2001 Apr; 81(2):741-66.

7 Kalaria RN. The pathology and pathophysiology of vascular dementia. Neuropharmacology. 2018 May 15;134(Pt B):226-39.

8 Petersen RC. Mild cognitive impairment as a diagnostic entity. J Intern Med. 2004 Sep; 256(3):183-94.

9 Qiu C, Xu W, Fratiglioni L. Vascular and psychosocial factors in Alzheimer's disease: epidemiological evidence toward intervention. J Alzheimers Dis. 2010 May 26; 20(3):689-97.
10 Gupta A, Iadecola C. Impaired A $\beta$ clearance: a potential link between atherosclerosis and Alzheimer's disease. Front Aging Neurosci. 2015;7:115.

11 Øygarden H. Carotid intima-media thickness and prediction of cardiovascular disease. J Am Heart Assoc. 2017 Jan 21;6(1): e005313.

12 Gorelick PB, Scuteri A, Black SE, Decarli C, Greenberg SM, Iadecola C, et al. Vascular contributions to cognitive impairment and dementia: a statement for healthcare professionals from the American heart association/American stroke association. Stroke. 2011 Sep;42(9):2672-713.

13 Fazekas F, Chawluk JB, Alavi A, Hurtig HI, Zimmerman RA. MR signal abnormalities at $1.5 \mathrm{~T}$ in Alzheimer's dementia and normal aging. Am J Roentgenol. 1987 Aug; 149(2):351-6.

14 Xie B, Shi X, Xing Y, Tang Y. Association between atherosclerosis and Alzheimer's disease: a systematic review and meta-analysis. Brain Behav. 2020 Apr;10(4):e01601.

15 Urbanova B, Tomek A, Mikulik R, Magerova $\mathrm{H}$, Horinek D, Hort J. Neurosonological examination: a non-invasive approach for the detection of cerebrovascular impairment in AD. Front Behav Neurosci. 2014;8: 4.

16 Zhong W, Cruickshanks KJ, Schubert CR, Acher CW, Carlsson CM, Klein BE, et al. Carotid atherosclerosis and 10-year changes in cognitive function. Atherosclerosis. 2012 Oct;224(2):506-10.

17 Moon JH, Lim S, Jang HC, Kim KM, Choi SH, Park KS, et al. Response to letter regarding article, "carotid intima-media thickness is associated with the progression of cognitive impairment in older adults". Stroke. 2015 Apr;46(4):e176-30.
18 Gustavsson AM, van Westen D, Stomrud E, Engström G, Nägga K, Hansson O. Midlife atherosclerosis and development of $\mathrm{Al}$ zheimer or vascular dementia. Ann Neurol. 2020 Jan; $87(1): 52-62$.

19 Higgins JPT, Thomas J, Chandler J, Cumpston M, Li T, Page MJ . Cochrane handbook for systematic reviews of interventions version 6.2 (updated February 2021): Cochrane; 2021. Available from: www.training.cochrane.org/handbook.

20 Review Manager (RevMan). (Computer program). Version 5.4. The Cochrane Collaboration; 2020.

21 CASP (Cohort Study) Checklist. [Internet]. [cited 2021 Apr 1]. Available from: insert URL

22 Center for evidence based management (July, 2014), critical appraisal checklist for cross-sectional study. [cited 2021 Apr 1]. Available from: https://www.cebma.org.

23 Schünemann $\mathrm{H}$, Brożek J, Guyatt G, Oxman A. GRADE handbook for grading quality of evidence and strength of recommendations: The GRADE Working Group; 2013.

24 Bell CC. DSM-IV: diagnostic and statistical manual of mental disorders. JAMA. 1994 Sep 14;272(10):828.

25 Folstein MF, Folstein SE, McHugh PR. "Mini-mental state". A practical method for grading the cognitive state of patients for the clinician. J Psychiatr Res. 1975 Nov; 12(3):189-98

26 Matsumoto L, Suzuki K, Mizuno Y, Ohike Y, Ozeki A, Ono S, et al. Association of subclinical carotid atherosclerosis with immediate memory and other cognitive functions. Geriatr Gerontol Int. 2018 Jan;18(1): 65-71. 
27 Tachibana H, Washida K, Kowa H, Kanda F, Toda T. Vascular function in Alzheimer's disease and vascular dementia. Am J Alzheimers Dis Other Demen. 2016 Aug; 31(5):437-42.

28 Casado Naranjo I, Portilla Cuenca JC Duque de San Juan B, García AF, Sevilla RR, Serrano Cabrera A, et al. Association of vascular factors and amnestic mild cognitive impairment: a comprehensive approach. J Alzheimers Dis. 2015;44(2):695704.

29 Chen RH, Jiang XZ, Zhao XH, Qin YL, Gu $\mathrm{Z}, \mathrm{Gu} \mathrm{PL}$, et al. Risk factors of mild cognitive impairment in middle aged patients with type 2 diabetes: a cross-section study. Ann Endocrinol. 2012 Jun;73(3):208-12.

30 Dias Eda M, Giollo LT, Martinelli DD, Mazeti C, Júnior HM, Vilela-Martin JF, et al. Carotid intima-media thickness is associated with cognitive deficiency in hypertensive patients with elevated central systolic blood pressure. Cardiovasc Ultrasound. 2012 Oct 18;10:41.

31 Stefanova E, Pavlovic A, Jovanovic Z, Veselinovic N, Despotovic I, Stojkovic T, et al. Vascular risk factors in Alzheimer's disease - preliminary report. J Neurol Sci. 2012 Nov 15;322(1-2):166-9.

32 Sander K, Bickel H, Förstl H, Etgen T, Briesenick C, Poppert H, et al. Carotid-intima media thickness is independently associated with cognitive decline. The INVADE study. Int J Geriatr Psychiatry. 2010 Apr; 25(4):389-94.

33 Xiang J, Zhang T, Yang QW, Liu J, Chen Y, Cui M, et al. Carotid artery atherosclerosis is correlated with cognitive impairment in an elderly urban Chinese non-stroke population. J Clin Neurosci. 2013 Nov;20(11): 1571-5.

34 Park J, Park JH, Park H. Association between carotid artery intima-media thickness and combinations of mild cognitive impairment and pre-frailty in older adults. Int J Environ Res Public Health. 2019 Aug 19;16(16):2978.

35 Rouch L, Cestac P, Sallerin B, Andrieu S, Bailly $\mathrm{H}$, Beunardeau $\mathrm{M}$, et al. Pulse wave velocity is associated with greater risk of dementia in mild cognitive impairment patients. Hypertension. 2018 Nov; 72(5): 1109-16.

36 Viticchi G, Falsetti L, Vernieri F, Altamura C, Bartolini M, Luzzi S, et al. Vascular predictors of cognitive decline in patients with mild cognitive impairment. Neurobiol Aging. 2012 Jun;33(6):1127-9.

37 Cho K, Kim J, Kim GW. Changes in blood factors and ultrasound findings in mild cognitive impairment and dementia. Front Aging Neurosci. 2017 Dec 21;9:427.

38 Carcaillon L, Plichart M, Zureik M, Rouaud O, Majed B, Ritchie K, et al. Carotid plaque as a predictor of dementia in older adults: the three-city study. Alzheimers Dement. 2015 Mar;11(3):239-48.
39 Wang A, Chen G, Su Z, Liu X, Yuan X, Jiang $\mathrm{R}$, et al. Carotid intima-media thickness and cognitive function in a middle-aged and older adult community: a cross-sectional study. J Neurol. 2016 Oct;263(10): 2097-104.

40 Zeki Al Hazzouri A, Vittinghoff E, Sidney $\mathrm{S}$, Reis JP, Jacobs DR, Yaffe K. Intima-media thickness and cognitive function in stroke-free middle-aged adults: findings from the coronary artery risk development in young adults study. Stroke. 2015 Aug; 46(8):2190-6.

41 Lin HF, Huang LC, Chen CK, Juo SH, Chen CS. Carotid atherosclerosis among middleaged individuals predicts cognition: a 10 year follow-up study. Atherosclerosis. 2020 Dec;314:27-32.

42 Newman AB, Fitzpatrick AL, Lopez O, Jackson S, Lyketsos C, Jagust W, et al. Dementia and Alzheimer's disease incidence in relationship to cardiovascular disease in the cardiovascular health study cohort. J Am Geriatr Soc. 2005 Jul;53(7):1101-7.

43 van Oijen $\mathrm{M}$, de Jong FJ, Witteman JC, Hofman A, Koudstaal PJ, Breteler MM. Atherosclerosis and risk for dementia. Ann Neurol. 2007 May;61(5):403-10.

44 Wendell CR, Waldstein SR, Ferrucci L, O'Brien RJ, Strait JB, Zonderman AB. Carotid atherosclerosis and prospective risk of dementia. Stroke. 2012 Dec;43(12): 3319-24.

45 Suemoto CK, Nitrini R, Grinberg LT, Ferretti REL, Farfel JM, Leite REP, et al. Brazilian aging brain study group. Atherosclerosis and dementia: a cross-sectional study with pathological analysis of the carotid arteries. Stroke. 2011 Dec;42(12):3614-5.

46 Weimar C, Winkler A, Dlugaj M, Lehmann $\mathrm{N}$, Hennig F, Bauer M, et al. Ankle-brachial index but neither intima media thickness nor coronary artery calcification is associated with mild cognitive impairment. J Alzheimers Dis. 2015 Jul 24;47(2):433-42.

47 Camarda C, Pipia C, Azzarello D, Battaglini I, Romeo G, Chiodi M, et al. Vascular risk factors, vascular diseases, and imaging findings in a hospital-based cohort of mild cognitive impairment types. Curr Alzheimer Res. 2018;15(7):679-90.

48 de la Torre JC. Cerebral hemodynamics and vascular risk factors: setting the stage for Alzheimer's disease. J Alzheimers Dis. 2012;32(3):553-67.

49 Mataró M, Soriano-Raya JJ, López-Olóriz J, Miralbell J, Dacosta-Aguayo R. Cerebrovascular markers in lowered cognitive function. J Alzheimers Dis. 2014;42(Suppl 4):S383-91.

50 Romero JR, Beiser A, Seshadri S, Benjamin EJ, Polak JF, Vasan RS, et al. Carotid artery atherosclerosis, MRI indices of brain ischemia, aging, and cognitive impairment: the Framingham study. Stroke. 2009 May; 40(5):1590-6.
51 Bots ML, van Swieten JC, Breteler MM, de Jong PT, van Gijn J, Hofman A, et al. Cerebral white matter lesions and atherosclerosis in the Rotterdam Study. Lancet. 1993 May 15;341(8855):1232-7.

52 Hofman A, Ott A, Breteler MM, Bots ML, Slooter AJ, van Harskamp F, et al. Atherosclerosis, apolipoprotein $\mathrm{E}$, and prevalence of dementia and Alzheimer's disease in the Rotterdam study. Lancet. 1997 Jan 18; 349(9046): 151-4.

53 Kivipelto M, Helkala EL, Laakso MP, Hänninen $\mathrm{T}$, Hallikainen $\mathrm{M}$, Alhainen $\mathrm{K}$, et al. Apolipoprotein E epsilon4 allele, elevated midlife total cholesterol level, and high midlife systolic blood pressure are independent risk factors for late-life Alzheimer disease. Ann Intern Med. 2002 Aug 6; 137(3):149-55.

54 Alonso A, Mosley TH, Gottesman RF, Catellier D, Sharrett AR, Coresh J. Risk of dementia hospitalisation associated with cardiovascular risk factors in midlife and older age: the Atherosclerosis risk in communities (ARIC) study. J Neurol Neurosurg Psychiatry. 2009 Nov;80(11):1194201

55 Solomon A, Kivipelto M, Wolozin B, Zhou J, Whitmer RA. Midlife serum cholesterol and increased risk of Alzheimer's and vascular dementia three decades later. Dement Geriatr Cogn Disord. 2009;28(1):75-80.

$56 \mathrm{Li} \mathrm{J}$, Zhang M, Xu ZQ, Gao CY, Fang CQ, Deng J, et al. Vascular risk aggravates the progression of Alzheimer's disease in a Chinese cohort. J Alzheimers Dis. 2010; 20(2):491-500.

57 Gottesman RF, Schneider AL, Zhou Y, Coresh J, Green E, Gupta N, et al. Association between midlife vascular risk factors and estimated brain amyloid deposition. JAMA. 2017 Apr 11;317(14):1443-50.

58 Rajna Z, Mattila H, Huotari N, Tuovinen T, Krüger J, Holst SC, et al. Cardiovascular brain impulses in Alzheimer's disease. Brain. 2021 Mar 31;awab144.

59 Iadecola C. Neurovascular regulation in the normal brain and in Alzheimer's disease. Nat Rev Neurosci. 2004 May;5(5):347-60.

60 Park J, Park JH, Park H. Association between carotid artery intima-media thickness and combinations of mild cognitive impairment and pre-frailty in older adults. Int J Environ Res Public Health. 2019 Aug 19;16(16):2978

61 Matsumoto L, Suzuki K, Mizuno Y, Ohike Y, Ozeki A, Ono S, et al. Association of subclinical carotid atherosclerosis with immediate memory and other cognitive functions. Geriatr Gerontol Int. 2018 Jan;18(1): 65-71.

62 Rouch L, Cestac P, Sallerin B, Andrieu S, Bailly $\mathrm{H}$, Beunardeau $\mathrm{M}$, et al. Pulse wave velocity is associated with greater risk of dementia in mild cognitive impairment patients. Hypertension. 2018 Nov;72(5): 1109-16. 
63 Cho K, Kim J, Kim GW. Changes in blood factors and ultrasound findings in mild cognitive impairment and dementia. Front Aging Neurosci. 2017 Dec 21;9:427.

64 Tachibana H, Washida K, Kowa H, Kanda F, Toda T. Vascular function in Alzheimer's disease and vascular dementia. Am J Alzheimers Dis Other Demen. 2016 Aug; 31(5):437-42.

65 Casado Naranjo I, Portilla Cuenca JC, Duque de San Juan B, García AF, Sevilla RR, Serrano Cabrera A, et al. Association of vascular factors and amnestic mild cognitive impairment: a comprehensive approach. J Alzheimers Dis. 2015;44(2):695704.
66 Xiang J, Zhang T, Yang QW, Liu J, Chen Y, Cui $\mathrm{M}$, et al. Carotid artery atherosclerosis is correlated with cognitive impairment in an elderly urban Chinese non-stroke population. J Clin Neurosci. 2013 Nov;20(11): 1571-5.

67 Chen RH, Jiang XZ, Zhao XH, Qin YL, Gu $\mathrm{Z}, \mathrm{Gu} \mathrm{PL}$, et al. Risk factors of mild cognitive impairment in middle aged patients with type 2 diabetes: a cross-section study. Ann Endocrinol. 2012 Jun;73(3):208-12.

68 Dias Eda M, Giollo LT, Martinelli DD, Mazeti C, Júnior HM, Vilela-Martin JF, et al. Carotid intima-media thickness is associated with cognitive deficiency in hypertensive patients with elevated central systolic blood pressure. Cardiovasc Ultrasound. 2012 Oct 18;10:41.
69 Stefanova E, Pavlovic A, Jovanovic Z, Veselinovic N, Despotovic I, Stojkovic T, et al. Vascular risk factors in Alzheimer's disease - preliminary report. J Neurol Sci. 2012 Nov 15;322(1-2):166-9.

70 Viticchi G, Falsetti L, Vernieri F, Altamura C, Bartolini M, Luzzi S, et al. Vascular predictors of cognitive decline in patients with mild cognitive impairment. Neurobiol Aging. 2012 Jun;33(6):1127.e1-9.

71 Sander K, Bickel H, Förstl H, Etgen T, Briesenick C, Poppert H, et al. Carotid-intima media thickness is independently associated with cognitive decline. The INVADE study. Int J Geriatr Psychiatry. 2010 Apr; 25(4):389-94. 